\title{
New horizons for cutaneous microbiology: the role of biofilms in dermatological disease
}

\author{
N. Vlassova, A. Han, ${ }^{\star}$ J.M. Zenilman, $\dagger$ G. James $\ddagger$ and G.S. Lazarus* \\ Johns Hopkins School of Medicine, 733 N Broadway, Baltimore, MD 21205, U.S.A. \\ *Department of Dermatology, Johns Hopkins Medical Institutions, 2500 Mason F. Lord, 4940 Eastern Avenue, Baltimore, MD 21224-2780, U.S.A. \\ $\dagger$ Department of Medicine, Infectious Diseases Division, Johns Hopkins Medical Institutions, Baltimore, MD, U.S.A. \\ $\$$ Center for Biofilm Engineering, Montana State University, Bozeman, MT, U.S.A.
}

\section{Summary}

\section{Correspondence \\ Gerald S. Lazarus. \\ E-mail: glazaru1@jhmi.edu}

\section{Accepted for publication}

26 May 2011

\section{Funding sources}

None.

\section{Conflicts of interest}

None declared.

DOI $10.1111 / j .1365-2133.2011 .10458 . x$
Human skin is colonized by bacteria. The development of new genomic microbiological techniques has revealed that the bacterial ecology of human skin is far more complex than previously imagined and includes many fastidious or noncultivable bacterial species which are found on both normal and diseased skin. In nature, the predominant bacterial phenotype on epithelial surfaces is that of organisms organized within a biofilm. This contrasts with the widely held belief that bacteria are planktonic, i.e. free-floating single cells. Biofilms are sessile bacterial communities encased in an extracellular matrix that have a well-developed communication system and can regulate bacterial growth and metabolism, confer resistance to antimicrobials and to host inflammatory cells, and alter host metabolism. Biofilms have been observed on healthy skin and in a number of dermatological conditions, including some that were previously thought not to have an infectious aetiology. Here we review the concept of biofilms and their role in cutaneous health and disease.
New genomic techniques have revolutionized microbiology and have facilitated the identification of fastidious and noncultivable bacteria. Traditional culture approaches to skin microflora identified the major components as aerobic diphtheroids (Corynebacterium spp.), anaerobic diphtheroids (Propionibacterium acnes) and coagulase-negative staphylococci (CNS). ${ }^{1}$ Recent genomic analysis of disease-free skin found stable polymicrobial communities consisting predominantly of Pseudomonas and Janthinobacterium spp. ${ }^{2}$ Staphylococcus epidermidis and P. acnes constitute $<5 \%$ of microbiota. ${ }^{2}$

New technologies have also demonstrated that bacteria form biofilms on epithelial surfaces including skin. Biofilms are complex sessile microbial communities that consist of one or more bacterial species surrounded by extracellular polymeric substances (EPS). These bacterial communities attach to biological and nonbiological surfaces and demonstrate altered phenotypes and growth characteristics. ${ }^{3-7}$ Biofilms are now thought to be the predominant bacterial phenotype on both healthy and diseased human skin. ${ }^{8}$

Skin biofilms have been associated with several dermatological diseases such as acne, rosacea and atopic dermatitis (AD). Biofilms have also been shown to impair normal wound healing. These discoveries have prompted a shift toward a more targeted therapeutic approach based on the understanding of biofilm structure and organization as opposed to traditional culture-based therapies. It is becoming increasingly important for clinical dermatologists to understand the concept of biofilms, their role in cutaneous disorders and their influence on the choice of topical and systemic antimicrobials.

\section{Biofilm}

Bacteria exist in two states - planktonic and sessile - which differ significantly in their physiology, gene expression pattern and morphology. ${ }^{3}$ Almost all clinical microbiology is based on characterizing planktonic bacteria. In nature, however, most bacteria exist as biofilms, especially on epithelial surfaces. ${ }^{8-10}$ Transition from the planktonic form to biofilm is regulated by multiple environmental and physiological factors such as bacterial cell density and nutrient availability. ${ }^{3}$ Antimicrobials can have paradoxical effects. Some antibiotics in subminimum inhibitory concentrations (sub-MIC) enhance biofilm formation. For example, vancomycin and cefamandole induce biofilm production by CNS. ${ }^{11}$ Tobramycin, tetracycline and norfloxacin have the same effect on Pseudomonas aeruginosa cells. ${ }^{12}$ Gentamicin does not affect biofilm formation by Haemophilus influenzae but at sub-MIC it confers resistance to organisms within established biofilms. ${ }^{13}$ Conversely, other antibacterial agents such as azithromycin reduce $\mathrm{H}$. influenzae biofilm thickness 
and biomass ${ }^{14}$ and decrease production of virulence factors by P. aeruginosa biofilms ${ }^{14}$ even at sub-MIC.

Biofilms occur on a variety of natural surfaces such as teeth, ${ }^{15}$ heart valves, ${ }^{16}$ lungs of patients with cystic fibrosis $(\mathrm{CF})^{17}$ and middle ear mucosa in persistent otitis media. ${ }^{18}$ They are also found in chronic rhinosinusitis, ${ }^{19}$ prostatitis $^{20}$ and chronic osteomyelitis. ${ }^{21}$ Biofilms have been demonstrated on a number of nonbiological surfaces such as prosthetic heart valves, ${ }^{22}$ orthopaedic implants, ${ }^{23}$ intrauterine devices, ${ }^{24}$ contact lenses ${ }^{25}$ and intravenous catheters. ${ }^{26}$ Biofilms are also important in environmental microbiology.

Biofilm formation is a dynamic process. Many bacterial species reversibly attach to a solid surface within a few hours of inoculation (Fig. 1). ${ }^{4,27}$ Within the next few hours bacteria bind to the surface irreversibly, start multiplying and communicating with each other via quorum sensing (QS) molecules, form microcolonies and produce an extracellular matrix (ECM) around these colonies. ${ }^{28}$ The colonies may develop a variety of shapes and characteristics depending on local factors and bacterial species involved (Fig. 2). For example, 'small colony variant' strains of several staphylococcal species seen in chronic infections such as osteomyelitis and CF demonstrate features of biofilms. ${ }^{29-31}$ Eventually, certain areas of the biofilm detach, and free bacterial cells seed to other locations where they can form new biofilms. ${ }^{6,32}$

QS is a density-dependent form of cell-cell communication that represents a feedback loop regulating bacterial growth in which the bacterial cells synthesize and react to small signal molecules. ${ }^{33}$ QS allows microorganisms to sense when critical bacterial concentrations are attained. They then can suppress further multiplication by producing and releasing molecular

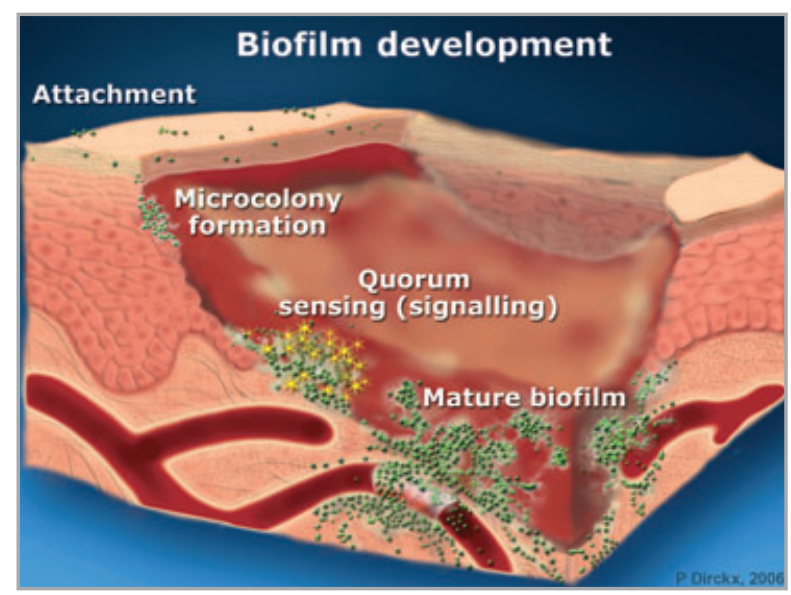

Fig 1. Process of biofilm development. The development of biofilms involves a characteristic sequence of events. The process begins with the initial attachment of bacteria to the surface, exchange of information via quorum sensing and production of extracellular polymers leading to the formation of microcolonies. During the subsequent maturation phase the amount of extracellular material increases and biofilms acquire antibiotic resistance. These steps are physiologically distinct and require phase-specific factors. ${ }^{44}$ (C) Center for Biofilm Engineering, Montana State University, Bozeman, MT, U.S.A. Reprinted with permission. signals that affect other bacterial cells, the host and the producer cells themselves. ${ }^{6,34}$ The QS mechanism largely comprises two distinct groups of signalling molecules. Peptide derivatives such as autoinducing peptides (AIP) are used by Gram-positive bacteria, whereas fatty acid derivatives such as acylhomoserine lactones and $\gamma$-butyrolactones are used by Gram-negative bacteria. ${ }^{35-38}$ Furanosyl diester (also known as autoinducer-2 or AI-2) is a signalling molecule that is expressed and recognized by both Gram-negative and -positive organisms; ${ }^{39}$ a notable exception is P. aeruginosa, which does not produce AI-2 but can respond to the molecule. ${ }^{40}$ The QS molecules exert their effect by regulating expression of genes involved in the production of virulence factors, sporulation, DNA uptake and biofilm formation. ${ }^{41}$ Unlike many QS systems described in Gram-negative biofilms, the two signalling systems of Staphylococcus aureus (agr and luxS) negatively regulate biofilm formation and virulence. ${ }^{42,43}$ The inactivation or downregulation of QS may be a crucial step in the development of S. aureus-associated infections ${ }^{42}$ of indwelling catheters, ${ }^{44}$ artificial joints, ${ }^{45}$ lungs of patients with $\mathrm{CF}^{46}$ and others.

QS may also have an effect on the eukaryotic host. For example, autoinducer signal molecule $\mathrm{N}$-(3-oxododecanoyl) homoserine lactone (3O- $\left.\mathrm{C}_{12}-\mathrm{HSL}\right)$ produced by $\mathrm{P}$. aeruginosa can stimulate production of interleukin (IL)-8 in bronchial epithelial cells in vitro, ${ }^{47,48}$ induce the expression of several cytokines (IL-6, IL- $1 \alpha$, etc.) that stimulate migration of monocytes, neutrophils and $\mathrm{T}$ cells in vitro and in vivo ${ }^{49}$ and upregulate the expression of cyclooxygenase- 2 in vitro. ${ }^{49}$ Interestingly, in vitro, 3O- $\mathrm{C}_{12}$-HSL can also inhibit lymphocyte proliferation and IL-12 production, important for the activation of macrophages. ${ }^{50}$ It is possible that $3 \mathrm{O}-\mathrm{C}_{12}-\mathrm{HSL}$ induces different immune responses depending on the environmental pressures and the type of host cells involved. ${ }^{51}$

QS was originally thought to be important for bacterial biofilm formation and virulence. While it has been shown that

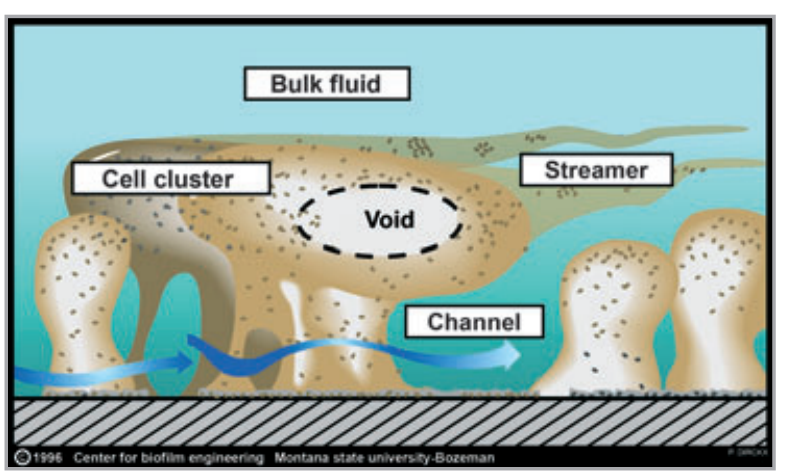

Fig 2. Heterogeneity of biofilm structure. Mature biofilms often have three-dimensional structures that are commonly described as 'towers' or 'mushrooms'. Fluid-filled channels found between these structures are thought to deliver nutrients to cells in deeper film layers. However, because of the wide range of microenvironments in which biofilms are found and the differences in physiological determinants such as substrates and metabolites the actual biofilm structures may vary significantly. ${ }^{9}$ (C) Center for Biofilm Engineering, Montana State University, Bozeman, MT, U.S.A. Reprinted with permission. 


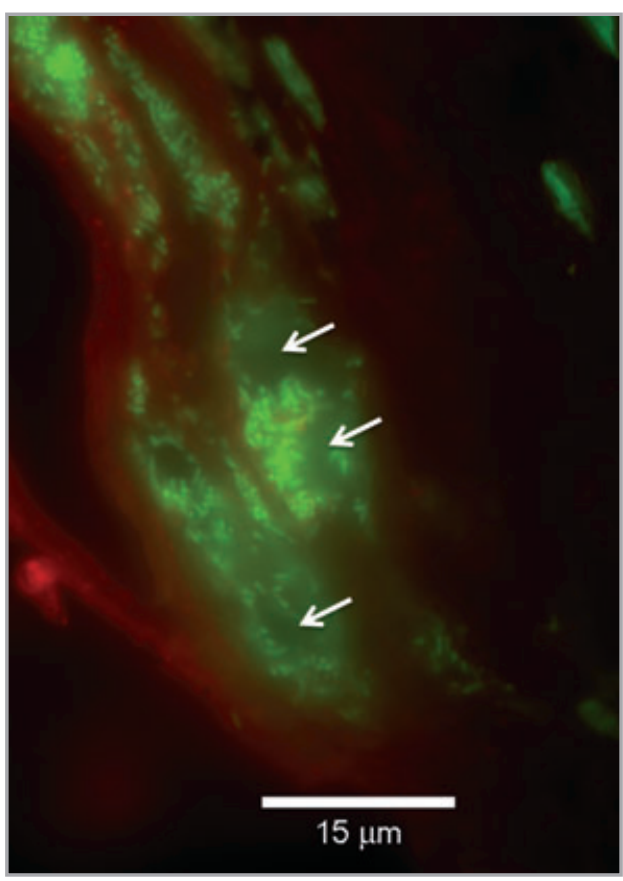

Fig 3. Biofilm structure. Fluorescence micrograph of a thin section from a human chronic wound showing biofilm formed by rod-shaped bacteria and the surrounding extracellular polymeric substances (EPS) (arrows). This specimen was stained with Sytox (green) and Phaseoulus vulgaris leucoagglutinin (red). The EPS is stained green due to extracellular bacterial DNA in the matrix. The lectin stained the connective tissue red. Microscopy by Margaret Campbell, Center for Biofilm Engineering. (C) Center for Biofilm Engineering, Montana State University, Bozeman, MT, U.S.A. Reprinted with permission.

P. aeruginosa strains lacking a functional QS system are less virulent than wild-type strains, ${ }^{52,53}$ biofilms formed by QS-deficient bacterial strains looked identical to those produced by wild-type strains. ${ }^{52}$ These data suggest that QS is crucial for P. aeruginosa virulence but not for biofilm formation.

The composition of EPS is complex (Fig. 3) and comprises polysaccharides, proteins, extracellular DNA and even hostproduced factors. ${ }^{9,43,54}$ The structure of the matrix varies considerably among species and even a single species can produce different EPS depending on growth conditions. ${ }^{43}$ In addition to structural functions, EPS also plays informative, redox-active and nutritive roles. ${ }^{54}$ Also, the cohesive strength of EPS determines the viscoelastic structure of biofilms. ${ }^{55}$ Unfortunately, the matrix is hard to image due to structural heterogeneity and the difficulty in distinguishing between microbial vs. host components of EPS. ${ }^{43,54}$

Several in vitro studies have shown that bacteria in biofilms are 50-500 times more resistant to antibiotics than their planktonic counterparts (Table 1). ${ }^{56-58}$ Multiple factors are thought to contribute to biofilm antibiotic resistance (Fig. 4):

1 Physical barrier. The ECM of the biofilm prevents diffusion of antibiotics through the biofilm matrix. ${ }^{59}$

2 Altered growth and metabolism. Growth, protein synthesis and metabolic activity are stratified in biofilms such that the highest level of activity happens at the surface with slow or no growth in the centre due to lack of nutrients and/or oxygen. ${ }^{60,61}$ Because most antimicrobials work by altering vital processes in dividing cells they have minimal effect on nonreproducing sessile microorganisms.

3 Phenotype switch. Sessile bacteria possess regulatory genes that integrate signals from the external environment and switch to more tolerant phenotypes upon environmental stresses such as increases in bacterial density, lack of nutrients or change in temperature and $\mathrm{pH}^{62}$

4 Increased mutation frequency and gene transfer. Mutation frequency in biofilm-growing bacteria is much higher than in free-floating organisms ${ }^{63}$ and is likely caused by oxidative stress resulting from slow, diffusion-limited release of reactive oxygen species $^{64}$ and a deficient antioxidant system. ${ }^{6,65}$ This high mutation frequency together with increased horizontal gene transmission in biofilms ${ }^{66}$ offers an explanation for quick development of multidrug resistance by sessile bacteria. The discovery of genomic islands accounting for up to $10 \%$ of the bacterial genome may further explain rapid changes in biofilm virulence potential. ${ }^{67}$ Genomic islands are horizontally acquired DNA segments frequently integrated in the vicinity of tRNA genes. ${ }^{68}$ When these DNA regions carry one or more virulence-associated genes they are called pathogenicity islands and they may have contributed to the evolution of the genome of multiple bacterial species. ${ }^{67}$
Table 1 Susceptibility of planktonic and biofilm bacteria to selected antibiotics

\begin{tabular}{|c|c|c|c|c|}
\hline References & Organism & Antibiotics & $\begin{array}{l}\text { MIC/MBC of } \\
\text { planktonic } \\
\text { phenotype } \\
\left(\mu \mathrm{gL} \mathrm{m}^{-1}\right)\end{array}$ & $\begin{array}{l}\text { Concentration } \\
\text { effective } \\
\text { against biofilm } \\
\text { phenotype } \\
\left(\mu \mathrm{g} \mathrm{mL}^{-1}\right)\end{array}$ \\
\hline Williams et al. ${ }^{121}$ & Staphylococcus aureus & Vancomycin & $2(\mathrm{MBC})$ & 20 \\
\hline Ceri et al. ${ }^{122}$ & Pseudomonas aeruginosa & Imipenem & 1 (MIC) & $>1024$ \\
\hline Ceri et al. ${ }^{122}$ & Escherichia coli & Ampicillin & 2 (MIC) & 512 \\
\hline Vorachit et al. ${ }^{123}$ & Pseudomonas pseudomallei & Ceftazidime & 8 (MBC) & 800 \\
\hline Larsen and Fiehn ${ }^{124}$ & Streptococcus sanguinis & Doxycycline & $0.063(\mathrm{MIC})$ & $3 \cdot 15$ \\
\hline
\end{tabular}




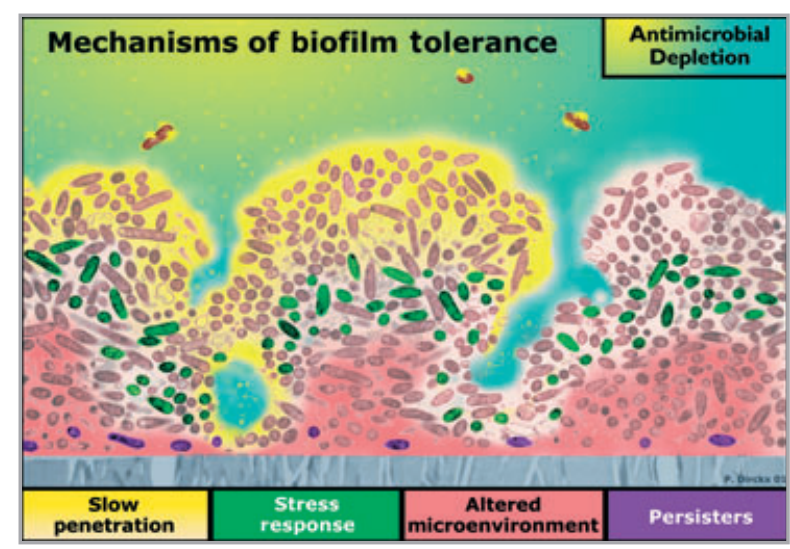

Fig 4. Mechanisms of antimicrobial tolerance. Biofilms confer resistance to antimicrobials by several different mechanisms. An increased proportion of nondividing 'persister cells' resistant to most antibiotics is believed to be one of them. Biofilm represents a natural stationary phase of bacterial life cycle during which microorganisms modify their growth and metabolism as well as mutation frequency and gene transfer. ${ }^{43}$ In addition, the extracellular matrix acts as a diffusion barrier to small molecules. (C) Center for Biofilm Engineering, Montana State University, Bozeman, MT, U.S.A. Reprinted with permission.

5 Spore-like forms. Biofilms often contain so-called 'persister cells' that are virtually impossible to eradicate with any antibiotic. Persisters are spore-like cells that produce proteins that shut down antibiotic targets. For example, cells that shut down the ribosome become tolerant to aminoglycosides whereas cells that prevent peptidoglycan synthesis develop resistance to cell wall-acting antibiotics. ${ }^{69}$

Besides inducing antibiotic tolerance, biofilms may contribute to increased bacterial virulence. ${ }^{3}$ In P. aeruginosa, multiple virulence factors are expressed during biofilm formation. ${ }^{70,71}$ Conversely, S. aureus virulence factors are downregulated during biofilm growth. ${ }^{42}$ Paradoxically, this may represent a pathogenic mechanism because biofilm growth, unnoticed by the immune system, produces a higher number of nonvirulent bacteria that are released, and subsequently become virulent. ${ }^{51,72}$ Furthermore, biofilms affect phagocytosis. Polymorphonuclear leucocytes can penetrate biofilm but cannot effectively internalize individual bacteria. ${ }^{73}$ This dysfunctional phagocytosis results in production of increased quantities of inflammatory cytokines that contribute to chronic inflammation and destruction of the surrounding tissues. ${ }^{73}$

\section{Bacterial biofilms and skin}

\section{Wounds}

A fertile area of study of skin biofilm pathophysiology is wounds. 16S rRNA gene-based analysis demonstrated an average of 10 different bacterial families in various chronic wounds or about four times more than estimated by cultures. ${ }^{74}$ Fastidious anaerobic bacteria belonging to the Clostridiales family were among the most prevalent organisms but were only identified by molecular analysis. ${ }^{74}$ High-throughput pyrosequencing showed increased proportions of anaerobes, Gram-negative rods and Gram-positive cocci but a decreased proportion of Propionibacterium in chronic wounds vs. normal skin (A. Han, J.M. Zenilman, J.H. Melendez et al., unpublished data).

Several studies employing molecular techniques confirmed abundance of anaerobes such as Bacteroides, Peptoniphilus, Finegoldia and Anaerococcus in diabetic ${ }^{75}$ and venous stasis ulcers. ${ }^{76}$ Dowd et al. ${ }^{75}$ showed that obligate anaerobes represented $62 \%$ of the bacteria in pressure ulcers. In all the studies, cultures successfully identified only the nonfastidious, easily 'culturable' organisms such as S. aureus. Therefore, if an organism cannot be detected by culture, it cannot be assumed to be absent, because of the comparatively low sensitivity of standard cultures.

Other technologies have helped describe biofilm morphology. Transmission electron microscopy revealed that S. epidermidis grows as a biofilm between the squamous cells of normal skin. ${ }^{8}$ Numerous studies have also demonstrated the presence of biofilms in chronic wounds. ${ }^{76-79}$ James et al. ${ }^{80}$ detected biofilms in $60 \%$ of chronic wounds and only $6 \%$ of acute wounds. Biofilms impair wound healing as they induce local immune dysfunction and apoptosis in keratinocytes, alter production of enzymes and growth factors by endothelial cells, impair neovascularization, and inhibit fibroblast synthesis, migration and proliferation. ${ }^{78,81}$ The structure of a biofilm depends on several factors including its bacterial composition. In biofilms consisting of mixed flora, anaerobes are most likely located in the centre of the biofilm while aerobes are found closer to the surface. The microelectrode profiles of tonsilloliths that are morphologically similar to biofilms demonstrated a stratification of physiological activity. ${ }^{82}$ Oxygen consumption in the top layers depleted oxygen deeper in the tonsillolith suggesting the presence of anaerobes in the centre of this biofilm-like structure. ${ }^{82}$

Although biofilms are commonly associated with pathological processes they may also play a protective role. Donlan and Costerton $^{8}$ suggested that all mammals have symbiotic relationships with specific staphylococcal species residing on their skin. The host provides his staphylococci with 'food and lodging' while the bacteria protect their partner by competing with potential pathogens. ${ }^{8}$ Moreover lipoteichoic acid produced by $S$. epidermidis was shown to act on keratinocytes triggered by Toll-like receptor (TLR)-3 and hence to inhibit skin inflammation. ${ }^{83}$ In addition, a small molecule produced by $S$. epidermidis was found to activate TLR2 and increase production of antimicrobial peptides thus enhancing antimicrobial defence. ${ }^{84} \mathrm{~A}$ better understanding of the biofilm composition and structure will lead to the development of optimal infection management and treatment strategies. Antimicrobials should be used judiciously because antibiotic overuse especially at sub-MIC can be deleterious. As mentioned earlier, certain antibiotics at sub-MIC enhance the formation of biofilms. ${ }^{11,12,14}$ Analysis of P. aeruginosa isolated from the lungs of patients with CF revealed that treatment with amikacin, ceftaz- 
idime and levofloxacin, even at doses higher than MIC, selected for resistant variants. ${ }^{85}$ Reinhardt et al. ${ }^{86}$ prospectively collected P. aeruginosa tracheal isolates from two intubated patients treated with carbapenem, fluoroquinolone or combined $\beta$-lactam aminoglycosides. Resistance appeared within 10 days of the initiation of treatment with any class of antibiotics $^{86}$ suggesting that P. aeruginosa forms biofilms in the lungs of patients with $\mathrm{CF}$ and those who have been intubated. ${ }^{17,87}$ Persister cells that exhibit multidrug tolerance can evolve and may be impossible to eradicate. ${ }^{88}$ Antibiotics eliminate both pathogenic and commensal organisms and thus allow persister cells to proliferate in the absence of competition. In an effort to limit the selective pressure of antimicrobials some authors propose treating ventilator-associated pneumonia for 8 days instead of $15 .^{86,89}$

\section{Biofilms in dermatological conditions}

There is a significant difference between the microbial flora of diseased and healthy skin. For example, use of broad-range 16S rDNA polymerase chain reaction demonstrated that Firmicutes was the most abundant phylum in psoriatic lesions $(46 \cdot 2 \%)$ as opposed to healthy skin $(24 \cdot 4 \%) \cdot{ }^{90}$ A biofilm from a patient with rosacea was shown to contain more Demodex folliculorum and P. acnes than a biofilm of a healthy individual. ${ }^{91}$ New molecular techniques have also changed our ideas about 'normal' skin flora. Firstly, there is topographical diversity of the human skin microbiome. Physiologically comparable sites are colonized by similar bacterial communities, which may explain why certain dermatological disorders occur at stereotypical skin sites. $^{2}$ Secondly, sequencing of bacterial $16 \mathrm{~S}$ small-subunit rRNA genes from the skin of healthy volunteers revealed that the genera Pseudomonas and Janthinobacterium represented the majority of the sequences. Conversely, S. epidermidis and P. acnes represented $<5 \%$ of microbiota. ${ }^{2}$ These findings contradict the commonly held notion that Pseudomonads are secondary wound invaders while S. epidermidis and P. acnes are the main commensal aerobes.

Certain inflammatory dermatological conditions that have traditionally been thought not to be infectious may in fact have an infectious aetiology. As mentioned above, the fact that bacteria cannot be cultured from a skin lesion does not mean that microorganisms are not present. Instead they may represent difficult-to-culture species or they may be present in biofilms. This fact can explain why certain 'noninfectious' diseases respond to antibiotics and relapse following the discontinuation of treatment. Acne vulgaris, miliaria and $\mathrm{AD}$ have long been classified as noninfectious but are now thought to be associated with biofilms.

\section{Acne vulgaris}

Acne vulgaris is a common cutaneous disorder affecting over $80 \%$ of teenagers. ${ }^{92}$ The initial step in acne pathogenesis is believed to be hyperplasia of pilosebaceous ducts with formation of keratinaceous plugs and subsequent colonization of the follicle by P. acnes. ${ }^{80,93}$ Some authors propose that P. acnes should be found in the pilosebaceous units as biofilms rather than free-floating bacteria. ${ }^{5,94}$ Although P. acnes biofilms have never been directly observed in the pilosebaceous unit this bacterium can form biofilms in vitro ${ }^{95-97}$ and in vivo on a number of medical devices. ${ }^{98}$ Also, the complete genome sequence of P. acnes has revealed three separate clusters of genes that encode enzymes involved in EPS biosynthesis, adhesion proteins and the homologue of luxS (ORF405), responsible for the production of the QS molecule AI-2. ${ }^{92}$ Treatment options such as photodynamic therapy designed to damage P. acnes biofilms are being investigated with promising results. $^{99}$

\section{Miliaria}

Miliaria or heat rash is caused by obstruction of the eccrine ducts leading to sweat retention in different layers of the epidermis. Mowad et al. ${ }^{100}$ inoculated the forearms of healthy subjects with several strains of CNS under occlusion. Of all the CNS tested only the EPS-producing strains of S. epidermidis induced miliaria. Given this finding and the fact that the sweat glands were found to be obstructed by EPS, the authors concluded that $S$. epidermidis and its ability to form biofilms play a role in the pathogenesis of miliaria.

\section{Atopic dermatitis}

$\mathrm{AD}$ is a chronic skin disorder associated with abnormalities in skin barrier function and allergen sensitization. ${ }^{101}$ Although healthy skin flora only rarely contains S. aureus this pathogen is frequently isolated from AD lesions. ${ }^{102-104}$ Akiyama et al. ${ }^{105}$ proposed that S. aureus in these lesions could be forming biofilm-like structures. Using confocal laser scanning microscopy (CLSM) they observed the formation of biofilms by $\mathrm{S}$. aureus strains isolated from $\mathrm{AD}$ lesions in vitro and in vivo. ${ }^{106,107}$ Katsuyama et al. ${ }^{108}$ collected the stratum corneum of their patients with $\mathrm{AD}$ and confirmed the presence of S. aureus biofilm in the lesions with scanning electron microscopy.

\section{Onychomycosis}

Onychomycosis is a common chronic nail infection caused by Trichophyton rubrum, T. mentagrophytes and some Candida spp. ${ }^{109,110}$ Dermatophytoma is a complication of onychomycosis that negatively affects the chance of cure. ${ }^{111}$ Burkhart et al. ${ }^{112}$ proposed that fungal biofilms contributed to resistance of dermatophytomas to antifungal therapy. The ability of dermatophytes to form biofilms has not yet been investigated but several species of yeast have been shown to form biofilms. ${ }^{13,114}$ In addition, histological examination of nail clippings in onychomycosis demonstrated resting spores mixed with actively growing hyphae. ${ }^{115}$ This finding is consistent with the description of biofilms in which many cells exist in a dormant state. 


\section{Impetigo and furuncles}

Finally, impetigo and furuncles represent acute infectious disorders that have been shown to be associated with sessile bacterial colonies. Impetigo is a superficial infection of the skin caused by group A streptococci or S. aureus. ${ }^{116}$ Furuncles are perifollicular abscesses caused by S. aureus. ${ }^{116}$ Akiyama et al. ${ }^{117}$ observed formation of periodic acid-Schiff-positive and Ruthenium red-positive structures around S. aureus cells isolated from impetigo and furuncle lesions in vitro. Two studies by the same team later demonstrated the formation of glycocalyx by $S$. aureus isolated from furuncle and impetigo lesions in vivo. ${ }^{18,119}$ The researchers also studied S. pyogenes and S. aureus biofilms in nonbullous impetigo lesions in vivo. Using CLSM they found that S. pyogenes cells formed microcolonies encircled by glycocalyx in the outer walls of the lesions and that these colonies existed independently from microcolonies formed by S. aureus. ${ }^{120}$

\section{Conclusions}

Human skin is a major interface with the outside world. It is colonized by an astonishing number and variety of microorganisms. New molecular technologies have provided us with opportunities to understand the role of bacteria in cutaneous health and disease. These new methods have also demonstrated that the conventional wisdom derived from culture data is often not adequate to establish pathophysiological relationships. Recent research suggests that bacterial biofilms may be critical to our understanding of the pathogenesis of skin disorders and their treatment as biofilm appears to be the predominant bacterial phenotype on the skin that can alter host responses as well as bacterial susceptibility to antibiotics. Therefore, it is likely that in the near future biofilms will rewrite the role of bacteria in skin disease.

\section{What's already known about this topic?}

- Human skin is colonized by bacteria.

- New molecular techniques have demonstrated that the cutaneous microflora is far more complex than previously appreciated.

- Biofilms are the predominant bacterial phenotype in nature.

\section{What does this study add?}

- Biofilms have been observed in dermatological conditions and may be important in the pathogenesis of skin disorders.

- Inappropriate use of antibiotics can enhance biofilm formation.

- Better understanding of biofilm composition and structure will lead to development of optimal treatment strategies.

\section{References}

1 Bisno AL. Cutaneous infections: microbiologic and epidemiologic considerations. Am J Med 1984; 15:172-9.

2 Grice EA, Kong HH, Renaud G et al. A diversity profile of the human skin microbiota. Genome Res 2008; 18:1043-50.

3 Landini P, Antoniani D, Burgess JG, Nijland R. Molecular mechanisms of compounds affecting bacterial biofilm formation and dispersal. Appl Microbiol Biotechnol 2010; 86:813-23.

4 Davis SC, Ricotti C, Cazzaniga A et al. Microscopic and physiologic evidence for biofilm-associated wound colonization in vivo. Wound Repair Regen 2008; 16:23-9.

5 Burkhart CN, Burkhart CG. Microbiology's principle of biofilms as a major factor in the pathogenesis of acne vulgaris. Int J Dermatol 2003; 42:925-7.

6 Hoiby N, Bjarnsholt T, Givskov M et al. Antibiotic resistance of bacterial biofilms. Int J Antimicrob Agents 2010; 35:322-32.

7 Martin JM, Zenilman JM, Lazarus GS. Molecular microbiology: new dimensions for cutaneous biology and wound healing. J Invest Dermatol 2010; 130:38-48.

8 Donlan RM, Costerton JW. Biofilms: survival mechanisms of clinically relevant microorganisms. Clin Microbiol Rev 2002; 15:167-93.

9 Sutherland IW. The biofilm matrix - an immobilized but dynamic microbial environment. Trends Microbiol 2001; 9:222-7.

10 Wolcott RD, Ehrlich GD. Biofilms and chronic infections. JAMA 2008; 299:2682-4.

11 Dunne WM. Effects of subinhibitory concentrations of vancomycin or cefamandole on biofilm production by coagulase-negative staphylococci. Antimicrob Agents Chemother 1990; 34:390-3.

12 Linares JF, Gustafsson I, Baquero F, Martinez JL. Antibiotics as intermicrobial signaling agents instead of weapons. Proc Natl Acad Sci USA 2006; 103:19484-9.

13 Starner TD, Shrout JD, Parsek MR et al. Subinhibitory concentrations of azithromycin decrease nontypeable Haemophilus influenzae biofilm formation and diminish established biofilms. Antimicrob Agents Chemother 2008; 52:137-45.

14 Skindersoe ME, Alhede M, Phipps $\mathrm{R}$ et al. Effects of antibiotics on quorum sensing in Pseudomonas aeruginosa. Antimicrob Agents Chemother 2008; 52:3648-63.

15 Periasamy S, Kolenbrander PE. Mutualistic biofilm communities develop with Porphyromonas gingivalis and initial, early, and late colonizers of enamel. J Bacteriol 2009; 191:6804-11.

16 Presterl E, Grisold AJ, Reichmann S et al. Viridans streptococci in endocarditis and neutropenic sepsis: biofilm formation and effects of antibiotics. J Antimicrob Chemother 2005; 55:45-50.

17 Bjarnsholt T, Jensen PØ, Fiandaca MJ et al. Pseudomonas aeruginosa biofilms in the respiratory tract of cystic fibrosis patients. Pediatr Pulmonol 2009; 44:547-58.

18 Hall-Stoodley L, Hu FZ, Gieseke A et al. Direct detection of bacterial biofilms on the middle-ear mucosa of children with chronic otitis media. JAMA 2006; 296:202-11.

19 Sanderson AR, Leid JG, Hunsaker D. Bacterial biofilms on the sinus mucosa of human subjects with chronic rhinosinusitis. Laryngoscope 2006; 116:1121-6.

20 Mazzoli S. Biofilms in chronic bacterial prostatitis (NIH-II) and in prostatic calcifications. FEMS Immunol Med Microbiol 2010; 59:33744.

21 Brady RA. Osteomyelitis and the role of biofilms in chronic infection. FEMS Immunol Med Microbiol 2008; 52:13-22.

22 Jones JW, Paull SN. Effect of biofilm culture on antibiotic susceptibility of lactobacilli causing endocarditis. J Infect 1995; 31:80-1.

23 Trampuz A, Zimmerli W. Prosthetic joint infections: update in diagnosis and treatment. Swiss Med Wkly 2005; 135:243-51. 
24 Auler ME, Morreira D, Rodrigues FF et al. Biofilm formation on intrauterine devices in patients with recurrent vulvovaginal candidiasis. Med Mycol 2010; 48:211-16.

25 Zegans ME, Shanks RM, O’Toole GA. Bacterial biofilms and ocular infections. Ocul Surf 2005; 3:73-80.

26 Raad I, Chatzinikolaou I, Chaiban G et al. In vitro and ex vivo activities of minocycline and EDTA against microorganisms embedded in biofilm on catheter surfaces. Antimicrob Agents Chemother 2003; 47:3580-5.

27 Werthen M, Henriksson L, Jensen PØ et al. An in vitro model of bacterial infections in wounds and other soft tissues. APMIS 2010; 118:156-64.

28 Mack D. Molecular mechanisms of Staphylococcus epidermidis biofilm formation. J Hosp Infect 1999; 43 (Suppl.):S113-25.

29 Wright JA, Nair SP. Interaction of staphylococci with bone. Int J Med Microbiol 2010; 300:193-204.

30 von Eiff C, Peters G, Becker K. The small colony variant (SCV) concept - the role of staphylococcal SCVs in persistent infections. Injury 2006; 37 (Suppl. 2):S26-33.

31 Kahl B, Herrmann M, Everding AS et al. Persistent infection with small colony variant strains of Staphylococcus aureus in patients with cystic fibrosis. J Infect Dis 1998; 177:1023-9.

32 Costerton JW, Stewart PS, Greenberg EP. Bacterial biofilms: a common cause of persistent infections. Science 1999; 284:131822.

33 Bjarnsholt T, Givskov M. The role of quorum sensing in the pathogenicity of the cunning aggressor Pseudomonas aeruginosa. Anal Bioanal Chem 2007; 387:409-14.

34 Decho AW, Norman RS, Visscher PT. Quorum sensing in natural environments: emerging views from microbial mats. Trends Microbiol 2010; 18:73-80.

35 Czajkowski R, Jafra S. Quenching of acyl-homoserine lactonedependent quorum sensing by enzymatic disruption of signal molecules. Acta Biochim Pol 2009; 56:1-16.

36 Fuqua C, Greenberg EP. Listening in on bacteria: acyl-homoserine lactone signalling. Nat Rev Mol Cell Biol 2002; 3:685-95.

37 Waters CM, Bassler BL. Quorum sensing: cell-to-cell communication in bacteria. Annu Rev Cell Dev Biol 2005; 21:319-46.

38 Bassler BL, Losick R. Bacterially speaking. Cell 2006; 125:237-46.

39 Raina S, De Vizio D, Odell $M$ et al. Microbial quorum sensing: a tool or a target for antimicrobial therapy? Biotechnol Appl Biochem 2009; 54:65-84.

40 Duan K, Dammel C, Stein J et al. Modulation of Pseudomonas aeruginosa gene expression by host microflora through interspecies communication. Mol Microbiol 2003; 50:1477-91.

41 Camilli A, Bassler BL. Bacterial small-molecule signaling pathways. Science 2006; 311:1113-16.

42 Kong KF, Vuong C, Otto M. Staphylococcus quorum sensing in biofilm formation and infection. Int $J$ Med Microbiol 2006; 296:133-9.

43 López D, Vlamakis H, Kolter R. Biofilms. Cold Spring Harb Perspect Biol 2010; 2:a00039.

44 Otto M. Staphylococcal biofilms. Curr Top Microbiol Immunol 2008; 322:207-28.

45 Neut D, van der Mei HC, Bulstra SK, Busscher HJ. The role of small-colony variants in failure to diagnose and treat biofilm infections in orthopedics. Acta Orthop 2007; 78:299-308.

46 O’Malley CA. Infection control in cystic fibrosis: cohorting, crosscontamination, and the respiratory therapist. Respir Care 2009; 54:641-57.

47 Smith RS, Fedyk ER, Springer TA et al. IL-8 production in human lung fibroblasts and epithelial cells activated by the Pseudomonas autoinducer N-3-oxododecanoyl homoserine lactone is transcrip- tionally regulated by NF-kappa B and activator protein-2. J Immunol 2001; 167:366-74.

48 DiMango E, Zar HJ, Bryan R, Prince A. Diverse Pseudomonas aeruginosa gene products stimulate respiratory epithelial cells to produce interleukin-8. J Clin Invest 1995; 96:2204-10.

49 Smith RS, Kelly R, Iglewski BH, Phipps RP. The Pseudomonas autoinducer N-(3-oxododecanoyl) homoserine lactone induces cyclooxygenase-2 and prostaglandin E2 production in human lung fibroblasts: implications for inflammation. J Immunol 2002; 169:2636-42.

50 Telford G, Wheeler D, Williams $P$ et al. The Pseudomonas aeruginosa quorum-sensing signal molecule N-(3-oxododecanoyl)-L-homoserine lactone has immunomodulatory activity. Infect Immun 1998; 66:36-42.

51 Smith RS, Iglewski BH. Pseudomonas aeruginosa quorum sensing as a potential antimicrobial target. J Clin Invest 2003; 112:1460-5.

52 Schaber JA. Pseudomonas aeruginosa forms biofilms in acute infection independent of cell-to-cell signaling. Infect Immun 2007; 75:371521.

53 Rumbaugh KP, Griswold JA, Iglewski BH et al. Contribution of quorum sensing to the virulence of Pseudomonas aeruginosa in burn wound infections. Infect Immun 1999; 67:5854-62.

54 Flemming HC, Neu TR, Wozniak DJ. The EPS matrix: the 'house of biofilm cells'. J Bacteriol 2007; 189:7945-7.

55 Stoodley P, Cargo R, Rupp CJ et al. Biofilm material properties as related to shear-induced deformation and detachment phenomena. J Ind Microbiol Biotechnol 2002; 29:361-7.

56 Nickel JC, Ruseska I, Wright J et al. Tobramycin resistance of Pseudomonas aeruginosa cells growing as a biofilm on urinary catheter material. Antimicrob Agents Chemother 1985; 27:619-24.

57 Prosser BL, Taylor D, Dix BA, Cleeland R. Method of evaluating effects of antibiotics on bacterial biofilm. Antimicrob Agents Chemother 1987; 31:1502-6.

58 Mah TF, O’Toole GA. Mechanisms of biofilm resistance to antimicrobial agents. Trends Microbiol 2001; 9:34-9.

59 Anderson GG, O’Toole GA. Innate and induced resistance mechanisms of bacterial biofilms. Curr Top Microbiol Immunol 2008; 322:85-105.

60 Werner E, Roe F, Bugnicourt A et al. Stratified growth in Pseudomonas aeruginosa biofilms. Appl Environ Microbiol 2004; 70:6188-96.

61 Keren I, Kaldalu N, Spoering A et al. Persister cells and tolerance to antimicrobials. FEMS Microbiol Lett 2004; 230:13-18.

62 Novick RP. Autoinduction and signal transduction in the regulation of staphylococcal virulence. Mol Microbiol 2003; 48:142949.

63 Driffield K, Miller K, Bostock JM et al. Increased mutability of Pseudomonas aeruginosa in biofilms. J Antimicrob Chemother 2008; 61:1053-6.

64 Burne RA, Quivey RG Jr, Marquis RE. Physiologic homeostasis and stress responses in oral biofilms. Methods Enzymol 1999; 310:441-60.

65 Mandsberg LF, Ciofu O, Kirkby $\mathrm{N}$ et al. Antibiotic resistance in Pseudomonas aeruginosa strains with increased mutation frequency due to inactivation of the DNA oxidative repair system. Antimicrob Agents Chemother 2009; 53:2483-91.

66 Molin S, Tolker-Nielsen T. Gene transfer occurs with enhanced efficiency in biofilms and induces enhanced stabilisation of the biofilm structure. Curr Opin Biotechnol 2003; 14:255-61.

67 Spencer DH, Kas A, Smith EE et al. Whole-genome sequence variation among multiple isolates of Pseudomonas aeruginosa. J Bacteriol 2003; 185:1316-25.

68 Battle SE, Rello J, Hauser AR. Genomic islands of Pseudomonas aeruginosa. FEMS Microbiol Lett 2009; 290:70-8. 
69 Lewis K. Persister cells and the riddle of biofilm survival. Biochemistry (Mosc) 2005; 70:267-74.

70 Wagner VE, Li LL, Isabella VM, Iglewski BH. Analysis of the hierarchy of quorum-sensing regulation in Pseudomonas aeruginosa. Anal Bioanal Chem 2007; 387:469-79.

71 Wagner VE, Gillis RJ, Iglewski BH. Transcriptome analysis of quorum-sensing regulation and virulence factor expression in Pseudomonas aeruginosa. Vaccine 2004; 22 (Suppl. 1):S15-20.

72 Karatan E, Watnick P. Signals, regulatory networks, and materials that build and break bacterial biofilms. Microbiol Mol Biol Rev 2009; 73:310-47.

73 Leid JG, Shirtliff ME, Costerton JW, Stoodley P. Human leukocytes adhere to, penetrate, and respond to Staphylococcus aureus biofilms. Infect Immun 2002; 70:6339-45.

74 Price LB, Liu CM, Melendez JH et al. Community analysis of chronic wound bacteria using 16S rRNA gene-based pyrosequencing: impact of diabetes and antibiotics on chronic wound microbiota. PLOS ONE 2009; 4:e6462.

75 Dowd SE, Sun Y, Secor PR et al. Survey of bacterial diversity in chronic wounds using pyrosequencing, DGGE, and full ribosome shotgun sequencing. BMC Microbiol 2008; 8:43.

76 Malic S, Hill KE, Hayes A et al. Detection and identification of specific bacteria in wound biofilms using peptide nucleic acid fluorescent in situ hybridization (PNA FISH). Microbiology 2009; 155:2603-11.

77 Bjarnsholt T, Kirketerp-Møller K, Jensen PØ et al. Why chronic wounds will not heal: a novel hypothesis. Wound Repair Regen 2008; 16:2-10.

78 Kirker KR, Secor PR, James GA et al. Loss of viability and induction of apoptosis in human keratinocytes exposed to Staphylococcus aureus biofilms in vitro. Wound Repair Regen 2009; 17:690-9.

79 Kirketerp-Møller K, Jensen PØ, Fazli M et al. Distribution, organization, and ecology of bacteria in chronic wounds. J Clin Microbiol 2008; 46:2717-22.

80 James GA, Swogger E, Wolcott $R$ et al. Biofilms in chronic wounds. Wound Repair Regen 2008; 16:37-44.

81 Cunningham AB, Lennox JE, Ross RJ, eds. Biofilms: The Hypertextbook. Bozeman, MT: Center for Biofilm Engineering, Montana State University. 2011. Available at: http://biofilmbook.hypertextbookshop. com/public_version/ (last accessed 21 June 2011).

82 Stoodley P, Debeer D, Longwell M et al. Tonsillolith: not just a stone but a living biofilm. Otolaryngol Head Neck Surg 2009; 141:316-21.

83 Lai Y, Di Nardo A, Nakatsuji T et al. Commensal bacteria regulate Toll-like receptor 3-dependent inflammation after skin injury. Nat Med 2009; 15:1377-82.

84 Lai Y, Cogen AL, Radek KA et al. Activation of TLR2 by a small molecule produced by Staphylococcus epidermidis increases antimicrobial defense against bacterial skin infections. J Invest Dermatol 2010; 130:2211-21.

85 Drenkard E, Ausubel FM. Pseudomonas biofilm formation and antibiotic resistance are linked to phenotypic variation. Nature 2002; 416:740-3.

86 Reinhardt A, Köhler T, Wood P et al. Development and persistence of antimicrobial resistance in Pseudomonas aeruginosa: a longitudinal observation in mechanically ventilated patients. Antimicrob Agents Chemother 2007; 51:1341-50.

87 Favre-Bonté S, Chamot E, Köhler T et al. Autoinducer production and quorum-sensing dependent phenotypes of Pseudomonas aeruginosa vary according to isolation site during colonization of intubated patients. BMC Microbiol 2007; 7:33.

88 Lewis K. Multidrug tolerance of biofilms and persister cells. Curr Top Microbiol Immunol 2008; 322:107-31.
89 Chastre J, Wolff M, Fagon JY et al. Comparison of 8 vs 15 days of antibiotic therapy for ventilator-associated pneumonia in adults: a randomized trial. JAMA 2003; 290:2588-98.

90 Gao Z, Tseng CH, Strober BE et al. Substantial alterations of the cutaneous bacterial biota in psoriatic lesions. PLoS ONE 2008; 3:e27 19

91 Draelos ZD. Treating beyond the histology of rosacea. Cutis 2004; 3 (Suppl.):28-34.

92 Brüggemann $\mathrm{H}$, Henne $\mathrm{A}$, Hoster $\mathrm{F}$ et al. The complete genome sequence of Propionibacterium acnes, a commensal of human skin. Science 2004; 305:671-3.

93 Burkhart CG, Burkhart CN. Expanding the microcomedone theory and acne therapeutics: Propionibacterium acnes biofilm produces biological glue that holds corneocytes together to form plug. J Am Acad Dermatol 2007; 57:722-4.

94 Burkhart CN, Burkhart CG. Antibiotic-resistant Propionibacterium acnes may not be the major issue clinically or microbiologically in acne. Br J Dermatol 2003; 148:365-6.

95 Coenye T, Peeters E, Nelis HJ. Biofilm formation by Propionibacterium acnes is associated with increased resistance to antimicrobial agents and increased production of putative virulence factors. Res Microbiol 2007; 158:386-92.

96 Qi X, Gao J, Sun D et al. Biofilm formation of the pathogens of fatal bacterial granuloma after trauma: potential mechanism underlying the failure of traditional antibiotic treatments. Scand J Infect Dis 2008; 40:221-8.

97 Holmberg A, Lood R, Mörgelin M et al. Biofilm formation by Propionibacterium acnes is a characteristic of invasive isolates. Clin Microbiol Infect 2009; 15:787-95.

98 Coenye T, Honraet K, Rossel B et al. Biofilms in skin infections: Propionibacterium acnes and acne vulgaris. Infect Disord Drug Targets 2008; 8: 156-9.

99 James KA, Burkhart CN, Morrell DS. Emerging drugs for acne. Expert Opin Emerg Drugs 2009; 14:649-59.

100 Mowad CM, McGinley KJ, Foglia A et al. The role of extracellular polysaccharide substance produced by Staphylococcus epidermidis in miliaria. J Am Acad Dermatol 1995; 33:729-33.

101 Leung DYM, Eichenfield LF, Boguniewicz M. Atopic dermatitis (atopic eczema). In: Fitzpatrick's Dermatology in General Medicine (Wolff K, Goldsmith LA, Katz SI, Gilchrest BJ, Paller A, Leffell DJ, eds), 7th edn. 2008. New York: McGraw Hill, Chapter 14, online version.

102 Capoluongo E, Giglio AA, Lavieri MM et al. Genotypic and phenotypic characterization of Staphylococcus aureus strains isolated in subjects with atopic dermatitis. Higher prevalence of exfoliative B toxin production in lesional strains and correlation between the markers of disease intensity and colonization density. J Dermatol Sci $2001 ; 26: 145-55$.

103 Williams RE, Gibson AG, Aitchison TC et al. Assessment of a contact-plate sampling technique and subsequent quantitative bacterial studies in atopic dermatitis. Br J Dermatol 1990; 123:493-501.

104 Ogawa T, Katsuoka K, Kawano K, Nishiyama S. Comparative study of staphylococcal flora on the skin surface of atopic dermatitis patients and healthy subjects. J Dermatol 1994; 21:453-60.

105 Akiyama H, Tada J, Toi J et al. Changes in Staphylococcus aureus density and lesion severity after topical application of povidoneiodine in cases of atopic dermatitis. J Dermatol Sci 1997; 16:2330.

106 Akiyama H, Oono T, Huh WK et al. Actions of gluco-oligosaccharide against Staphylococcus aureus. J Dermatol 2002; 29:580-6.

107 Akiyama H, Hamada T, Huh WK et al. Confocal laser scanning microscopic observation of glycocalyx production by Staphylococcus aureus in skin lesions of bullous impetigo, atopic dermatitis and pemphigus foliaceus. Br J Dermatol 2003; 148:526-32. 
108 Katsuyama M, Ichikawa H, Ogawa S, Ikezawa Z. A novel method to control the balance of skin microflora. Part 1. Attack on biofilm of Staphylococcus aureus without antibiotics. J Dermatol Sci 2005; 38: 197-205.

109 Sommer S, Sheehan-Dare RA, Goodfield MJ, Evans EG. Prediction of outcome in the treatment of onychomycosis. Clin Exp Dermatol 2003; 28:425-8.

110 Trofa D, Gácser A, Nosanchuk JD. Candida parapsilosis, an emerging fungal pathogen. Clin Microbiol Rev 2008; 21:606-25.

111 Sigurgeirsson B. Prognostic factors for cure following treatment of onychomycosis. J Eur Acad Dermatol Venereol 2010; 24:679-84.

112 Burkhart CN, Burkhart CG, Gupta AK. Dermatophytoma: recalcitrance to treatment because of existence of fungal biofilm. J Am Acad Dermatol 2002; 47:629-31.

113 Reynolds TB, Fink GR. Bakers' yeast, a model for fungal biofilm formation. Science 2001; 291:878-81.

114 Oliveira MT, Specian AF, Andrade CG et al. Interaction of Candida parapsilosis isolates with human hair and nail surfaces revealed by scanning electron microscopy analysis. Micron 2010; 41:604-8.

115 Arrese JE, Piérard-Franchimont C, Piérard GE. Facing up to the diagnostic uncertainty and management of onychomycoses. Int J Dermatol 1999; 38 (Suppl. 2):1-6.

116 Craft N, Lee PK, Zipoli MT et al. Superficial cutaneous infections and pyodermas. In: Fitzpatrick's Dermatology in General Medicine (Wolff K, Goldsmith LA, Katz SI, Gilchrest BJ, Paller A, Leffell DJ, eds), 7th edn. 2008. New York: McGraw Hill, Chapter 177, online version.
117 Akiyama H, Ueda M, Kanzaki H et al. Biofilm formation of Staphylococcus aureus strains isolated from impetigo and furuncle: role of fibrinogen and fibrin. J Dermatol Sci 1997; 16:2-10.

118 Yamasaki O, Akiyama H, Toi Y, Arata J. A combination of roxithromycin and imipenem as an antimicrobial strategy against biofilms formed by Staphylococcus aureus. J Antimicrob Chemother 2001; 48:573-7.

119 Akiyama H, Huh WK, Yamasaki O et al. Confocal laser scanning microscopic observation of glycocalyx production by Staphylococcus aureus in mouse skin: does S. aureus generally produce a biofilm on damaged skin? Br J Dermatol 2002; 147:879-85.

120 Akiyama H, Morizane S, Yamasaki O et al. Assessment of Streptococcus pyogenes microcolony formation in infected skin by confocal laser scanning microscopy. J Dermatol Sci 2003; 32:193-9.

121 Williams I, Venable WA, Lloyd D et al. The effects of adherence to silicone surfaces on antibiotic susceptibility in Staphylococcus aureus. Microbiology 1997; 143:2407-13.

122 Ceri H, Olson ME, Stremick C et al. The Calgary Biofilm Device: new technology for rapid determination of antibiotic susceptibilities of bacterial biofilms. J Clin Microbiol 1999; 37:771-6.

123 Vorachit M, Lam K, Jayanetra P, Costerton JW. Resistance of Pseudomonas pseudomallei growing as a biofilm on silastic disks to ceftazidime and cotrimoxazole. Antimicrob Agents Chemother 1993; 37:2000-2.

124 Larsen T, Fiehn NE. Resistance of Streptococcus sanguis biofilms to antimicrobial agents. APMIS 1996; 104:280-4. 